\title{
LITERATUR REVIEW: PENGARUH TERAPI DISTRAKSI AUDIOVISUAL PADA SAAT PROSEDUR INJEKSI PADA ANAK USIA PRASEKOLAH SAAT HOSPITALISASI
}

\author{
Adi Mulyono ${ }^{1}$ \\ Politeknik Yakpermas Banyumas \\ Email adimulyono250@gmail.com \\ Puji Indriyani ${ }^{2}$ \\ Politeknik Yakpermas Banyumas \\ Email pj.indriyani@gmail.com \\ Rahaju Ningtyas ${ }^{3}$ \\ Politeknik Yakpermas Banyumas \\ Emailnningtyasrahaju@gmail.com ${ }^{3}$
}

\begin{abstract}
ABSTRAK
Latar belakang: Anak merupakan individu yang berada dalam satu rentang perubahan perkembangan yang dimulai dari bayi hingga remaja (Hidayat, 2009). Anak yang sedang sakit mempunyai respon berbeda, salah satunya yaitu anak akan mengalami kecemasan serta tidak bisa berinteraksi dengan orang lain, hal ini disebabkan karena anak harus menjalani proses perawatan di rumah sakit yang dikenal dengan proses hospitalisasi. Kecemasan merupakan perasaan yang paling umum dialami oleh pasien anak dengan hospitalisasi. Distraksi adalah metode untuk menghilangkan stress dan kecemasan dengan cara mengalihkan perhatian pada hal-hal lain sehingga pasien akan lupa terhadap cemas yang dialami. Tujuan: Untuk mendapatkan gambaran tentang pengaruh terapi distraksi audiovisual pada saat prosedur injeksi pada anak usia prasekolah saat hospitalisasi. Metode: Desain yang digunakan pada penelitian ini adalah penelitian kepustakaan, sumber data yang diperoleh dari data sekunder dimana peneliti memperoleh sumber utama hasil literatur- literatur yang berkaitan dengan fokus kajian dari tahun 2015- 2020, dengan menggunakan 4 jurnal dan buku- buku yang membahas konsep keperawatan anak yang dijadikan sebagai referensi tetapi hanya 2 jurnal yang dijadikan sebagai landasan teori. Hasil: Dari kedua jurnal memberikan hasil bahwa terapi distraksi audiovisual sangat berpengaruh terhadap penurunan tingkat kecemasan dan tingkat nyeri pada anak usia prasekolah pada saat prosedur injeksi. Kesimpulan: Terapi distraksi audiovisual sangat berpengaruh terhadap penurunan tingkat kecemasan dan tingkat nyeri pada anak usia prasekolah pada saat prosedur injeksi.
\end{abstract}

Kata kunci : Anak usia prasekolah, Hospitalisasi, Terapi Distraksi, Kecemasan, Tingkat nyeri

\section{ABSTRACT}

Background: Children are individuals who are in a range of developmental changes starting from infancy to adolescence (Hidayat, 2009). Children who are sick have different responses, one of which is that the child will experience anxiety and cannot interact with other people, this is because the child has to undergo a treatment process at the hospital known as the hospitalization process. Anxiety is the most common feeling experienced by pediatric patients with hospitalization. Distraction is a method to relieve stress and anxiety by diverting attention to other things so that the patient will forget about the anxiety experienced. Objective: To get an overview of the effect of audiovisual distraction therapy during injection procedures in preschool children during hospitalization. Methods: The design used in this study is library research, data sources obtained from secondary data where the researchers obtained the main source of literature related to the focus of the study from 2015-2020, using 4 journals and books that discuss the concept nursing children are used as a reference but only 2 journals are used as a theoretical basis. Results: Both journals provide results that audiovisual distraction therapy is very influential on reducing anxiety levels and pain levels in preschool children during the injection procedure. Conclusion: Audiovisual distraction therapy is very influential in reducing anxiety levels and pain levels in preschool children during the injection procedure. 
Adi Mulyono : Literatur Review: Pengaruh Terapi Distraksi Audiovisual Pada Saat Prosedur Injeksi Pada Anak Usia Prasekolah Saat Hospitalisasi

Keywords: Preschool children, hospitalization, distraction therapy, anxiety, pain level

\section{PENDAHULUAN}

Anak merupakan individu yang berada dalam satu rentang perubahan perkembangan yang dimulai dari bayi hingga remaja (Hidayat, 2009). Anak yang sedang sakit mempunyai respon berbeda, salah satunya yaitu anak akan mengalami kecemasan serta tidak bisa berinteraksi dengan orang lain, hal ini disebabkan karena anak harus menjalani proses perawatan di rumah sakit yang dikenal dengan proses hospitalisasi. Beragam perasaan dapat muncul pada anak sejalan dengan efek hospitalisasi.

Hospitalisasi bagi anak dan orang tua akan menimbulkan strees dan merasa tidak aman. Susilowati (2009) juga mengemukakan tentang efek stress tergantung pada persepsi anak dan orang tua terhadap penyakit dan pengobatan. Hasil penelitian Purwandari (2011) di RSUD Margono Soekarjdo Purwokerto menunjukan $25 \%$ anak usia prasekolah yang dirawat mengalami cemas tingkat berat, $50 \%$ tingkat sedang dan $25 \%$ tingkat ringan. Hasil penelitian yang dilakukan oleh Cut (2012) yang dilakukan di Rumah Sakit Anak dan Bunda Harapan Kita Jakarta, juga menunjukan $47,5 \%$ dari 40 anak mengalami stress sedang, dengan tanda-tanda sulit tidur, mudah lelah, kurang bersemangat dalam aktivitas, sulit buang air besar dan buang air kecil.

Kecemasan pada anak ditandai dengan menangis, dan takut pada orang baru. Lingkungan rumah sakit juga dapat menjadi penyebab stress dan kecemasan anak (Utami, 2014). Cemas pada anak usia prasekolah yang menjalani proses hospitalisasi sering disebabkan oleh perpisahan dengan orang tua, rasa takut pada nyeri dan cedera tubuh, serta kehilangan aktivitasnya, misalnya bermain, dengan tanda-tanda sulit tidur, mudah lelah, kurang bersemangat dalam aktivitas, sulit buang air besar dan air kecil (Chusniyah \& Santy 2016).

Kecemasan yang dialami anak prasekolah dalam masa hospitalisasi merupakan masalah yang penting, jika tidak ditangani dapat berpengaruh dalam proses tumbuh kembang. Asuhan keperawatan pada anak biasanya memerlukan tindakan invasif seperti injeksi atau pemasangan infus, hal ini merupakan stresor kuat yang dapat membuat anak mengalami kecemasan. Perawat biasanya akan menjelaskan prosedur ini kepada orang tua dan melakukan komunikasi terapeutik kepada anak sebelum melakukan prosedur tersebut, kondisi ini juga membuat anak menjadi panik dan biasanya melakukan perlawanan atau menolak untuk dilakukan prosedur pemasangan infus atau injeksi obat, sehingga berakibat timbulnya trauma pada anak.

Distraksi adalah metode untuk menghilangkan stress dan kecemasan dengan cara mengalihkan perhatian pada hal-hal lain sehingga pasien akan lupa terhadap cemas yang dialami. Stimulus sensori yang menyenangkan menyebabkan pelepasan endorfin yang bisa menghambat stimulus cemas yang mengakibatkan lebih sedikit stimuli cemas yang ditransmisikan ke otak (Potter \& Perry, 2010).

Menurut Wong (2009), distraksi yang dapat dilakukan yaitu melibatkan anak dalam permainan. Bermain di rumah sakit hendaknya yang tidak membutuhkan banyak energi, waktu 
Adi Mulyono : Literatur Review: Pengaruh Terapi Distraksi Audiovisual Pada Saat Prosedur Injeksi Pada Anak Usia Prasekolah Saat Hospitalisasi

singkat, mudah dilakukan, aman serta tidak mengganggu terapi.Macammacam alat permainan yang dapat dilakukan untuk teknik distraksi dalam pengalihan nyeri yaitu radio, tape recorder, $\mathrm{CD}$ player atau permainan komputer, gunakan humor seperti menonton kartun atau cerita lucu (Wong, 2009).

Media audio visual adalah merupakan media perantara atau penggunaan materi dan penyerapan melalui pandangan dan pendengaran sehingga membangun kondisi yang dapat memperoleh keterampilan, pengetahuan, dan sikap. Audiovisual yang digemari oleh anak-anak usia pre-school adalah kartun atau gambar bergerak, merupakan media yang sangat menarik bagi anak-anak terutama anak usia pre-school yang memiliki daya imajinasi tinggi. Audio visual dapat memudahkan anak untuk medapatkan pembelajaran dengan basis menyenangkan. Anak juga dapat mengeksplorasi perasaan, emosi, dan daya ingat melalui audio visual, audio visual juga dapat membantu perawat dalam melaksanakan prosedur infus dan injeksi, memudahkan perawat dalam mendistraksi agar anak kooperatif dalam pelaksanaan prosedur terapi (Taufik, 2010). Dengan demikian diharapkan pengalaman nyeri pada anak berkurang dan mengurangi proses dari kecemasan akibat prosedur pemasangan infus

Oleh karena itu penulis sangat tertarik untuk melakukan penelitian dengan pendekatan melakukan suatu terapi atau tindakan keperawatan dalam bentuk karya ilmiah dengan judul terapi distraksi untuk anak usia prasekolah terhadap trauma prosedur injeksi saat hospitalisasi selama masa perawatan di RSUD Dr. R. Goeteng Taroenadibrata Purbalingga. Penulis berharap dengan adanya terapi distraksi ini mampu meminimalkan anak usia prasekolah yang mengalami hospitalisasi selama masa perawatan serta dapat memberikan pengetahuan ibu dalam melakukan perawatan pada anak yang mengalami hospitalisasi dengan terapi distraksi.

\section{METODE PENELITIAN}

Jenis penelitian ini adalah penelitian kepustakaan yaitu penelitian dengan mengkaji atau meninjau secara kritis pengetahuan, gagasan, atau temuan yang terdapat dalam literature akademik dengan mencari referensi teori yang relefan dengan kasus atau permasalahan yang ditemukan. Referensi teori yang di peroleh dijadikan sebagai fondasi dasar dan alat utama bagi praktek penelitian (Syaodah, 2015). Adapun sifat penelitian ini adalah analisis diskriptif, yaitu penguraian secara teratur data yang telah diperoleh dan kemudian diberikan pemahaman serta penjelasan agar dapat dipahami dengan baik oleh pembaca. Penelitian ini dilakukan tanggal 25 April 2020 sampai tanggal 13 Juli 2020.

Data yang digunakan dalam penelitian ini adalah data sekunder. Data sekunder adalah data yang diperoleh bukan dari pengamatan langsung, tetapi diperoleh dari hasil penelitian yang dilakukan oleh peneliti-peneliti sebelumnya, yang berupa buku dan laporan ilmiah dalam artikel atau jurnal.

Sumber utama pada penelitian ini adalah jurnal penelitian yang dilakukan oleh "Lilis Fatmawati, Yuanita Syaiful, Diyah Ratnawati" yang berjudul "Pengaruh Audiovisual Menonton Film Kartun Terhadap Tingkat Kecemasan Saat Prosedur Injeksi Pada Anak Prasekolah" yang diterbitkan pada tahun 2019 dengan 
alasan karena didalam jurnal tersebut tertera hasil penelitian yang menunjukan bahwa terapi distraksi menonton anime efektif untuk menurunkan kecemasan saat dilakukan tindakan injeksi.

Sumber kedua penelitian ini adalah jurnal penelitian yang dilakukan oleh "Vellyza colin, Buyung Keraman, Dian Dwianamaydinar, Mahdeli Prasensi" yang berjudul "Pengaruh Teknik Distraksi Menonton Kartun Animasi Terhadap Penurunan Skala Nyeri Saat Injeksi Pada Anak Usia Pra Sekolah" di terbitkan pada tahun 2020 dengan alasan karena didalam jurnal tersebut juga mengungkapkan hasil bahwa penerapan terapi distraksi menonton anim e efektif untuk menurunkan kecemasan atau tingkat nyeri pada anak usia prasekolah pada saat dilakukan injeksi

\section{Dokumentasi}

Dokumentasi merupakan metode untuk mencari dokumen atau data-data yang dianggp penting melalui artikel koran/majalah, jurnal, pustaka, brosur, buku dokumentasi serta melalui media elektronik yaitu internet, yang terkait rumusan masalah penelitian ini.

Studi Literatur

Studi literatur adalah cara yang dipakai untuk menghimpun data-data atau sumber-sumber yang berhubungan dengan topik yang diangkat dalam suatu penelitian. Studi literatur bisa didapat dari berbagai sumber, jurnal, buku dokumentasi, internet dan pustaka.

Data-data yang sudah diperoleh kemudian dianalisis dengan metode analisis deskriptif. Metode analisis deskriptif dilakukan dengan cara mendeskripsikan fakta-fakta yang kemudian dilanjutkan dengan analisis, tidak semata-mata menguraikan, melainkan juga memberikan pemahaman dan penjelasan secukupnya.

Prosedur penelitian ini melalui prosedur :

1. Organize, yaitu mengirganisir literatur yang akan ditinjau dengan dengan permasalahan dengan tahapan mencari ide, tujuan umum dan simpulam dari literatur dengan cara membaca abstark, beberapa pendahuluan dan kesimpulannya

2. Synthesize, menyatukan hasil organisir literatur menjadi suatu ringkasan agar menjadi satu kesatuan dan dengan mencari kertikatan antara literatur

3. Identity, yaitu mengidentifikasi isu-isu dalam literatdianggap sangat penting untuk dibahas dan dianalisis untuk medapatkan tulisan yang menarik ketika dibaca.

\section{HASIL DAN PEMBAHASAN}

Metode distraksi adalah suatu metode untuk menghilangkan nyeri dengan cara mengalihkan perhatian pasien pada hal-hal lain sehingga pasien akan lupa terhadap nyeri yang dialami (Andermoyo 2013). Ada beberapa kegiatan yang dapat dilakukan untuk menurunkan nyeri pada anak yang diberikan obat injeksi. Salah satu intervensi keperawatan yang bisa dilakukan adalah dapat menggunakan metode menonton kartun animasi.

Berdasarkan jurnal penelitian yang telah dianalisis oleh peneliti, maka peneliti menyimpulkan bahwa semua jurnal yang telah dianalisis 
Adi Mulyono : Literatur Review: Pengaruh Terapi Distraksi Audiovisual Pada Saat Prosedur Injeksi Pada Anak Usia Prasekolah Saat Hospitalisasi

mampu membuktikan adanya pengaruh penerapan terapi distraksi audiovisual menonton anime untuk menurunkan kecemasan dan rasa nyeri pada anak usia pra sekolah pada saat dilakukan tindakan prosedur injeksi. Pada jurnal pertama yang dilakukan di Ruang Anak Rumah Sakit Semen Gresik pada bulan Januari 2019 dengan total responden 28 anak. Pada jurnal pertama dalam pelaksanaan terapi distraksi menggunakan waktu selama minimal 10 menit. Hasil penelitian sebelum dilakukan terapi distraksi audiovisual pada saat prosedur injeksi pada anak usia prasekolah. sebagian besar anak mengalami tingkat kecemasan berat yang berjumlah 17 anak. Namun hasil penelitian sesudah dilakukan terapi distraksi audiovisual pada saat prosedur injeksi pada anak usia prasekolah yaitu hampir seluruhnya mengalami tidak cemas dengan jumlah 23 responden. Peneliti setelah menganalisis jurnal yang pertama mendapatkan adanya hambatan dalam penerapan terapi distraksi menonton film animasi karena dalam jurnal yang pertama dijelaskan masih adanya 1 responden yang mengalami kecemasan berat meskipun sudah diberikan terapi distraksi menonton anime. Hal ini dimungkinkan karena pasien mempunyai riwayat sudah pernah dirawat dua kali sebelumnya, sehingga pernah mempunyai pengalaman yang masih menjadi sumber kecemasan baginya, diantaranya pengalaman mendapatkan prosedur injeksi serta pemasangan infus.

Sedangkan pada jurnal kedua yang dilakukan di ruang Edelweis RSUD dr M. Yunus Bengkulu pada bulan Juli dan Agustus tahun 2019 dengan total responden sejumlah 30 anak usia prasekolah. Pada jurnal kedua dalam pelaksanaan penerapan terapi distraksi hanya membutuhkan waktu selama 2-3 menit. Peneliti menunjukan hasil sebelum dilakukan terapi distraksi audiovisual sebagian besar anak mengalami tingkat nyeri sedang dengan jumlah 17 anak dan anak dengan tingkat nyeri hebat berjumlah 8 anak, setelah hasil penelitian sesudah dilakukan terapi distraksi audiovisual menunjukan hampir keseluruhan anak mengalami tingkat nyeri ringan dengan jumlah 23 anak dan anak dengan tingkat nyeri hebat menjadi tidak ada.

Jadi penerapan terapi distraksi menonton kartun animasi ini berpengaruh efektif pada anak usia pra sekolah untuk menurunkan kecemasan dan atau nyeri saat prosedur injeksi. Didukung oleh pendapat Koller dan Goldman (2012) dalam studinya menyatakan bahwa pemberian cerita melalui audiovisual guna menurunkan kecemasan termasuk teknik distraksi kecemasan dengan teknik audiovisual. Perhatian anak yang terfokus kepada cerita audiovisual yang disimaknya mendis-traksikan atau mengalihkan persepsi kecemasan anak dalam korteks serebral. Hal tersebut sesuai dengan teori bahwa salah satu cara yang dapat dilakukan untuk pengendalian kecemasan adalah tehnik distraksi audiovisual untuk mengalihkan perhatian anak (Tamsuri, 2007, dalam Agustina 2015). Hasil penelitian ini sejalan dengan penelitian sebelumnya yang dilakukan oleh Padila (2019) yang menyebutkan, perlakuan terapi menonton kartun animasi mampu menurunkan tingkat kecemasan pada anak karena ketakutan anak menjadi berkurang, anak menjadi lebih akrab dangan perawat dan lebih familiar dengan lingkungan rumah sakit serta anak tidak akan merasa jenuh karena waktu 
mereka diisi dengan kegiatan menonton kartun animasi.

\section{KESIMPULAN}

Terapi distraksi adalah menonton anime, ada pengaruh penerapan terapi distraksi audiovisual terhadap tingkat kecemasan anak pada saat prosedur injeksi. Sebelum dilakukan terapi distraksi audiovisual anak mengalami tingkat kecemasan berat (skala 4). Dan setelah dilakukan terapi distraksi terdapat penurunan tingkat kecemasan menjadi tidak cemas (skala 1).

Presentase tingkat nyeri anak saat dilakukan prosedur injeksi sebelum dilakukan terapi audiovisual adalah tingkat nyeri sedang (skala 4-6) dan nyeri hebat (8-10) namun setelah dilakukan pemberian terapi distraksi audiovisual menjadi nyeri ringan skala (2-3).

\section{SARAN}

1. Bagi Rumah Sakit dan Perawat

Diharapkan Rumah Sakit dapat menyediakan alat yang lebih lengkap dan menyediakan alat pendukung seperti gadget untuk meningkatkan pelayanan keperawatan anak. Serta perawat dalam melaksanakan intervensi terapi distraksi menonton animasi sesuai SOP.

2. Bagi Penelitian Selanjutnya

Diharapkan dilakukan penelitian selanjutnya untuk menambah literatur dan memperpanjang waktu penelitian dengan menambah variabel serta intervensi yang mempengaruhi tingkat kecemasan dan ingkat nyeri pada anak usia prasekolah saat dilakukan prosedur injeksi dengan menggunakan metode penelitian yang lain.

\section{Bagi Keluarga}

Dengan literatur-literatur yang sudah ada diharapkan keluarga dapat ikut berperan aktif dalam pelaksanaan terapi distraksi menonton film animasi agar penerapan terapi distraksi bisa mendapatkan hasil yang maksimal.

\section{UCAPAN TERIMA KASIH}

1. Rahaju Ningtyas, S.Kp., M.Kep. selaku Direktur Politeknik Yakpermas Banyumas dan selaku pembimbing II.

2. Ns. Puji Indriyani, S.Pd., M.Kep., selaku pembimbing I yang dengan penuh kesabaran dan ketekunan memberikan dorongan, perhatian, bimbingan, pengarahan, serta saran dalam pembuatan karya tulis ilmiah ini mulai dari awal sampai akhir.

3. Bapak, ibu dosen serta staf Politeknik Yakpermas Banyumas yang telah membantu dalam penyusunan karya tulis ilmiah ini.

4. Orang tua saya dan keluarga yang telah memberikan motivasi, dorongan dan semangat dalam penulisan Karya Tulis Ilmiah ini.

5. Nur Azkia yang tak kenal lelah dalam mensupport dan membantu serta memberikan dukungan dan semangat dalam penyusunan Karya Tulis Ilmiah ini.

6. Teman- teman kelas Bayanaka 3C yang telah saling membantu dan mensupport dalam penyusunan Karya Tulis Ilmiah ini.

7. Teman dan Sahabatku "ORMUT" yang telah mensupport dalam penyusunan Karya Tulis Ilmiah ini.

\section{DAFTAR PUSTAKA}

\author{
Adriana, D. (2011). Tumbuh \\ kembang dan terapi bermain \\ pada anak. Jakarta: Salemba \\ Medika.
}


Adi Mulyono : Literatur Review: Pengaruh Terapi Distraksi Audiovisual Pada Saat Prosedur Injeksi Pada Anak Usia Prasekolah Saat Hospitalisasi

Chusniyah, N., \& Santy W.H. (2016). Pengaruh bimbingan imajinasi menggunakan media audio visual (video) terhadap stres hospitalisasi anak di RS islam Surabaya. Jurnal Ilmiah Kesehatan. Vol 9 (2), hal 200208.

Cut, (2012). Gambaran tingkat stres pada anak usia prasekolah selama hospitalisasi di Rumah Sakit Anak Harapan Kita Jakarta. Jurnal Keperawatan, 1 .

Gunarsa, S. D. (2012). Psikologi perkembangan anak dan remaja. BPK Gunung Mulia.

Hawari, Dadang. (2010). Manajemen stress, cemas, dan depresi. Jakarta : Fakultas Kedokteran Universitas Indonesia.

Hidayat, A. A. A. (2009). Pengantar ilmu keperawatan anak 1 . Jakarta : Salemba Medika.

(2012). Metode

Penelitian Keperawatan dan teknik analisa data. Jakarta: Salemba Medika.

Hurlock. (2012). Psikologi perkembangan (edisi ke lima). Jakarta: Erlangga.

Kaplan, H. I., Sadock, B. J., \& Grebb, J. A. (2010). Sinopsis psikiatri : Ilmu pengetahuan perilaku psikiatri klinis jilid 2. Jakarta: Bina Rupa Aksara.

Kusumawati, F., \& Hartono, Y (2010). Buku ajar keperawatan jiwa. Jakarta: Salemba Medika.
Kyle, T., \& Carman, S. (2015). Buku ajar keperawatan pediatrik edisi 2. Jakarta: Buku Kedokteran EGC.

Lilis Fatmawati, Yuanita Syaiful, Diyah Ratnawati. (2010). Pengaruh Audiovisual menonton film kartun terhadap tingkat kecemasan saat prosedur injeksi pada anak prasekolah. Jurnal Ilmiah Kesehatan (Journal of Health Sciences), Vol. 12, No. , Agustus 2019, Hal.15-29.

Mansjoer, Arif. (2010). Kapita selekta kedokteran jilid 2 edisi 3. Jakarta: Media Aesculapius.

Maramis. (2010). Catatan ilmu kedokteran jiwa edisi 2. Surabaya: Airlangga.

Notoatmodjo, S. (2010). Metodologi penelitian kesehatan. Jakarta: Rineka Cipta.

Nursalam, R. S., \& Utami, S. (2008). Asuhan keperawatan bayi dan anak. Jakarta: Salemba Medika.

Nursalam. (2009). Asuhan keperawatan bayi dan anak (cetakan ke II). Jakarta: Salemba Medika.

(2011). Konsep dan penerapan metodologi penelitian ilmu keperawatan edisi 2. Jakarta:EGC.

\section{(2013). Pendekatan} praktis metodologi riset keperawatan. Jakarta: CV Sagung Setyo.

Prasetyo. (2010). Konsep \& Proses keperawatan nyeri. Yogyakarta: Graha Ilmu 
Purwandari, H. (2011). Pengaruh terapi seni dalam menurunkan tingkat kecemasan anak usia prasekolah yang menjalani hospitalisasi di wilayah kabupaten Banyumas. Fakultas Ilmu Keperawatan.

Puspita, N. A., Armiyati, Y., \& Arif, S. (2014). Efektivitas pemberian terapi distraksi usia prasekolah untuk menurunkan tingkat kecemasan. Jurnal Kesehatan STIKES Darul Azhar Batulicin, $6(1)$.

Riduwan. (2009). Skala pengukuran dalam penelitian. Bandung: Alfabeta.

Soetjiningsih, (2013). Tumbuh kembang anak. Jakarta: EGC.

Sugiyono. (2010). Statistik untuk penelitian. Bandung: CV Alfabeta.

Supartini Y. (2009). Konsep dasar keperawatan. Jakarta: EGC.

konsep keperawatan anak.
$\begin{aligned} & \text { Jakarta: EGC. } \\ & \text { kaku ajar }\end{aligned}$

Susilowati. (2009). Pengukuran status gizi dengan antropometri gizi. Journal of Nutrition and Health, 1(1).

Taufik. (2010). Prinsip- prinsip promosi kesehatan dalam bidang keperawatan. Jakarta: CV Informatika.

Tamsuri A. (2009). Konsep \& Penatalaksanaan nyeri. Jakarta: EGC.
Utami, Y. (2014). Dampak hospitalisasi terhadap perkembangan anak. Jurnal Ilmiah Widya vol. 2 No.2; (920).

Vellyza colin, Buyung Keraman, Dian Dwianamaydinar, Mahdeli Prasensi. (2020). Pengaruh teknik distraksi menonton kartun animasi terhadap penurunan skala nyeri saat injeksi pada anak usia prasekolah. Jurnal Keperawatan Muhammadiyah Bengkulu, Volume 08, Nomor 01, April 2020.

Widiastuti. (2010). Jurnal Prosiding Conferensi Nasional PPNI Jawa Tengah: Efektifitas aroma terapi lavender dalam menurunkan nyeri \& kecemasan. Surakarta: Stikes PKU Muhammadiyah.

Windura. (2009). Memori dan pembelajaran aktif. Jakarta: Yrama Widya.

Wong, D.L. (2009). Buku ajar keperawatan pediatrik cetakan pertama. Jakarta: Penerbit buku kedokteran EGC. 